\title{
A high resolution geospatial database for wave energy exploitation
}

\author{
R. Carballo ${ }^{\mathrm{a}, *}$, M. Sánchez ${ }^{\mathrm{a}}$, V. Ramos ${ }^{\mathrm{a}}$, F. Taveira-Pinto ${ }^{\mathrm{b}}$, G. Iglesias ${ }^{\mathrm{c}}$ \\ ${ }^{a}$ Univ. of Santiago de Compostela, Hydraulic Eng., Campus Univ. s/n, 27002 Lugo, Spain \\ ${ }^{\mathrm{b}}$ Univ. of Porto, Faculty of Engineering, Rua Dr. Roberto Frias, 4200-465 Porto, Portugal \\ ${ }^{\mathrm{c}}$ Univ. of Plymouth, School of Marine Science and Engineering, Marine Building, Drakes Circus, Plymouth PL4 8AA, United Kingdom
}

\section{A R T I C L E I N F O}

\section{Article history:}

Received 14 October 2013

Received in revised form

30 December 2013

Accepted 24 February 2014

Available online 21 March 2014

\section{Keywords:}

Wave power

Database

Characterization matrix

Energy production

WEDGE

\begin{abstract}
A B S T R A C T
The estimation of energy production of a given WEC (wave energy converter) at a given coastal site is the basis for correct decision-making regarding wave energy exploitation in a coastal region. Nevertheless, the procedure followed by the conventional approach to characterize the wave energy resource does not provide the required information to obtain an accurate estimate. In this work, this information is provided for the region with the greatest resource in the Iberian Peninsula, the Death Coast (NW Spain). For this purpose, a geospatial database is produced by using a methodology which involves the consideration of virtually the totality of the resource together with the implementation of a high resolution spectral numerical model. In addition, a Matlab-based toolbox called WEDGE (Wave Energy Diagram GEnerator) is implemented to access the database and automatically generate high resolution energy diagrams (or characterization matrices) of the wave energy resource at any coastal location within this region. In this way, a precise computation of energy production of any WEC at any site of interest can now be performed. Finally, the functionality of the database is shown through a case study of a recently proposed wave farm.
\end{abstract}

(c) 2014 Elsevier Ltd. All rights reserved.

\section{Introduction}

The need for increasing the share of renewable energies to the total energy production has resulted in a growing interest in marine energies, amongst which wave energy has a great potential $[1,2]$. Wave energy is approaching viability as commercial power source as a result of the intensive research conducted over recent years to develop WECs (wave energy converters) [3]. This intensive research includes wave flume tests [4], 3D tank tests [5], the implementation of numerical models $[4,6]$ or parametric studies [7]. On the other hand, numerous assessments of the available resource were also performed with the aim of installing a wave farm. They covered areas with substantial resource such as UK [8], Spain [9,10], the Black Sea [11,12], Portugal [13,14] or US [15]. The greater part of these assessments was focused on quantifying the total available resource in a particular region, making available valuable information about the characteristics of their wave climate and of the most appropriate areas for wave energy exploitation. Nevertheless, it is necessary to bear in mind the final outcome that a wave energy resource assessment should provide: the elements for the estimation of energy production of any WEC at any location of interest in a coastal region. This arises from the need for comparing the energy

\footnotetext{
* Corresponding author. Tel.: +34 982 285900; fax: +34 982285926.

E-mail address: rodrigo.carballo@usc.es (R. Carballo).
}

production of different WECs at different locations within a coastal region and, on this basis, i) to select the WEC that performs best at each location of interest and ii) to define the location providing the largest energy production for a given technology. In consequence, the estimation of energy production is of crucial importance to determine the viability of a project. Unfortunately, the way in which most of the assessments were conducted over the last years gives rise to a lack of the elements needed to properly conduct this estimation.

The energy production of a WEC at a particular coastal location is the result of combining the power matrix of the selected WEC with the energy diagram or characterization matrix at the location, representing the available energy and occurrence for the different wave height and period combinations [16]. Within the typical procedure, followed by most of the resource assessments conducted, there are two factors that represent a limitation when it comes to obtaining a coastal characterization matrix [16,17]: i) the number of wave conditions considered (normally no more than a few wave cases or a mere determination of the amount of $\mathrm{kWm}^{-1}$ available in an average year) and ii) the resolution of the wave energy characterization parameters. This provokes that the resulting coastal wave energy resource information cannot be used for describing the resource in the form of a characterization matrix with the adequate level of resolution (the same as that of the power matrix of the WEC) for accurate energy production computations. 
In this work, there is developed a high resolution geospatial database of the wave energy resource throughout the most powerful coastal region in the Iberian Peninsula, the Death Coast (NW Spain) (Fig. 1) [18], following a comprehensive procedure which differs from the conventional methodology (Section 2). As a result, the information required for reconstructing high resolution characterization matrices at any coastal site is now available. Furthermore, a Matlab-based toolbox is implemented, giving easy access to the information stored and allowing the automatic computation of the characterization matrices with the adequate resolution. In Section 3, the interest of the database is shown through the analysis of a recently proposed area for the installation of a wave farm in this coastal region. Finally, in Section 4, the main conclusions of the present work are drawn.

\section{Database development}

The present database has been developed by implementing a methodology composed of different steps. Given its complexity, in Fig. 2, a complete flow chart is presented with the aim of guiding and signposting the reader through this Section.

\subsection{Characterization of the deepwater wave energy resource}

The first step towards the assessment of the wave climate in a coastal region is to investigate its deepwater climate and, on this basis, to determine the wave conditions of interest. In the case of the Death Coast, it can be accurately characterized by the VilánSisargas buoy located at approximately the middle point of the deepwater contour (Fig. 1). The dataset cover a period of around 14 years (1998-2012), comprising a total number of near 100,000 sea states with an hourly frequency.

For this purpose, the following spectral parameters of each sea state are computed from their hourly wave spectra: spectral wave height, $H_{\mathrm{m} 0}$, energy period, $T_{\mathrm{e}}$, and mean wave direction, $\theta_{\mathrm{m}} . H_{\mathrm{m} 0}$ is the spectral estimate of the significant wave height (or the average height of the highest $1 / 3$ of the waves of a sea state), $T_{\mathrm{e}}$ the period of a sinusoidal wave with the same energy as the sea state, and $\theta_{\mathrm{m}}$ the mean direction of the waves of the sea state.

They are computed respectively as follows [19]:

$H_{\mathrm{m} 0}=4\left(m_{0}\right)^{\frac{1}{2}}$

$T_{\mathrm{e}} \equiv T_{-10}=\frac{m_{-1}}{m_{0}}$

$\theta_{\mathrm{m}}=m_{0}^{-1} \int_{0}^{2 \pi} \int_{0}^{\infty} \theta S(f, \theta) d f d \theta$

where $m_{-1}$ and $m_{0}$ represent respectively the minus first and zeroth moments of the wave spectrum, and $S(f, \theta)$ the spectral energy density which specifies how energy is distributed as a function of frequencies $(f)$ and directions $(\theta)$. Next, the wave resource is characterized based on the probability distribution of the three aforementioned parameters (1-3) and using the concept of energy bin defined as trivariate intervals of significant wave height, energy
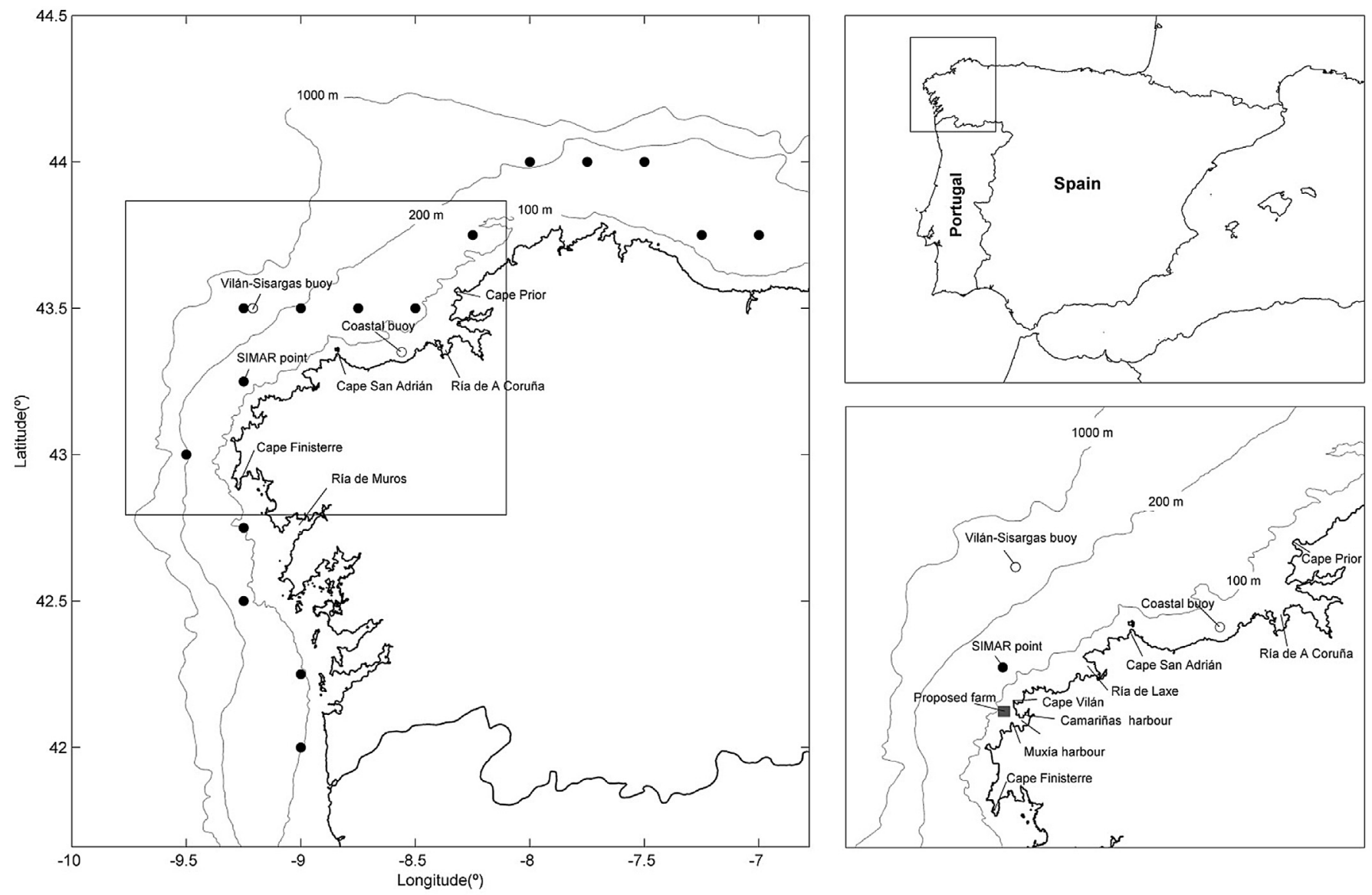

Fig. 1. Map of Galicia (left) in the NW of the Iberian Peninsula (above right), and the Death Coast region with a proposed area for a wave farm (below right). 


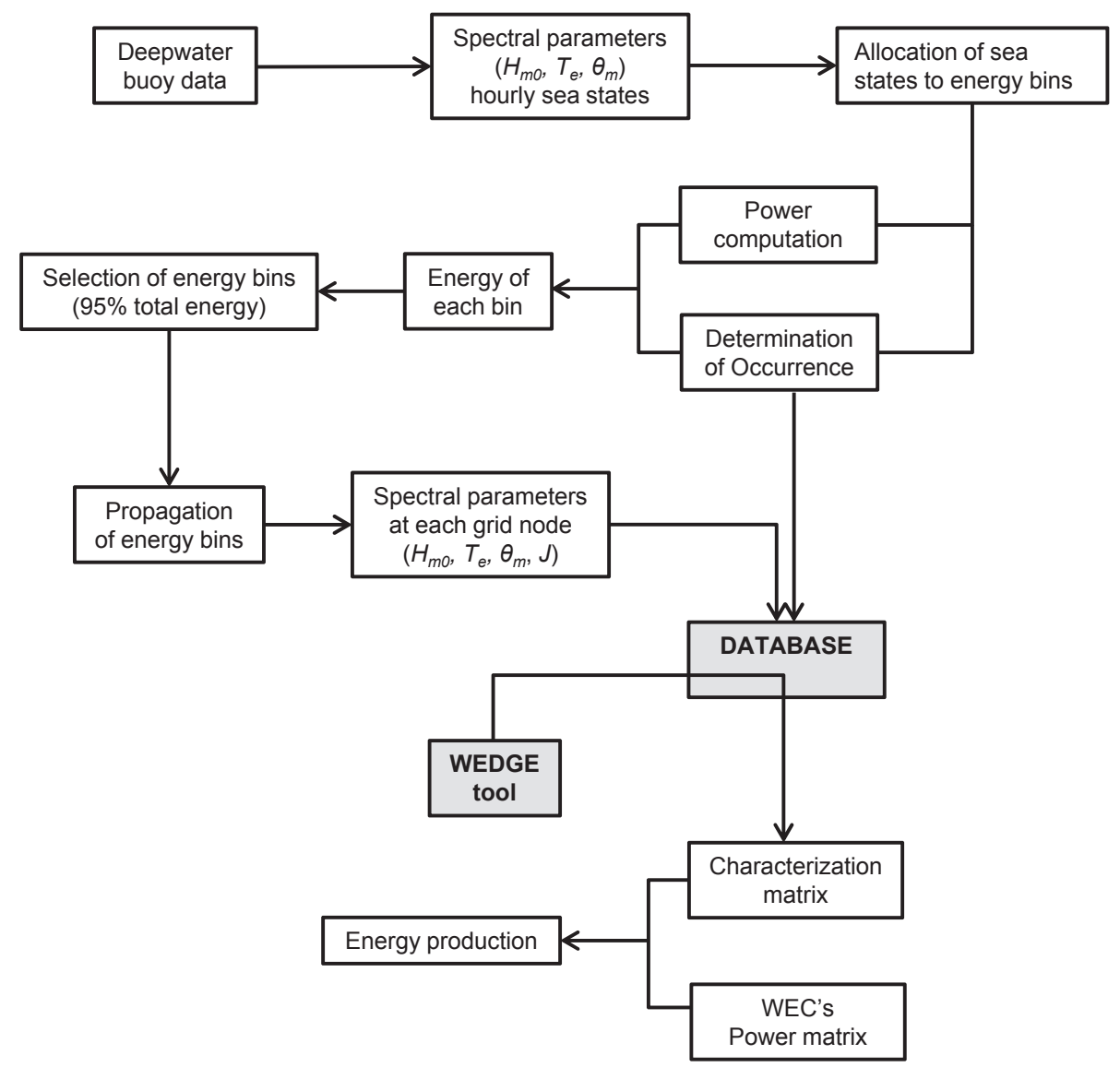

Fig. 2. Flow chart of the development of the database.

period, and wave direction [e.g. $H_{\mathrm{m} 0}=2-2.5 \mathrm{~m}, T_{\mathrm{e}}=8-8.5 \mathrm{~s}$, $\left.\theta_{\mathrm{m}}=326.25-348.75\right]$ [16].

A key aspect for a successful wave energy characterization is the selection of the adequate resolution or size of the energy bins. A concise way to present the predicted performance of a WEC is its power matrix - as the power curves in wind energy. It describes the WEC's performance for the different joint combinations of wave height and energy period. As stated, the actual energy that a WEC would produce at a site of interest is the result of combining its power matrix with the characterization matrix of the wave energy resource at that location. At present, two different power matrices can be provided by the different device developers: in terms of power output (Table 1) and in terms of efficiency (Table 2) for the different wave conditions (or energy bins). For energy production computations, the power matrix should be combined with the occurrence or with the total energy available of each energy bin specified by the characterization matrix depending on the information provided by the WEC developer (Table 1 or 2 , respectively). Despite that at the moment there is no information being provided by device developers regarding how wave direction affects the performance of WECs (or in other words, it is assumed that, in the case of offshore and nearshore devices, they swing with the change in the wave direction or, in the case of onshore devices, the waves approach the shore parallel to the bottom contours as a result of the refraction process), the deepwater wave direction needs to be taken into account for an accurate resource assessment, as it greatly affects the wave propagation process and thereby the distribution of the resource giving rise to areas of high and low energy concentration.

On these grounds, it emerges that the resolution of the energy bins of the characterization matrices at a point of interest should be at least of the same level than that of the power matrix of the

Table 1

Power matrix of a WEC in terms of power output $(\mathrm{kW})$.

\begin{tabular}{|c|c|c|c|c|c|c|c|c|c|c|c|c|}
\hline$H_{\mathrm{mo}}$ vs $T_{\mathrm{e}}$ & 5.0 & 6.0 & 7.0 & 8.0 & 9.0 & 10.0 & 11.0 & 12.0 & 13.0 & 14.0 & 15.0 & 16.0 \\
\hline 1.0 & 10 & 54 & 124 & 176 & 188 & 170 & 144 & 116 & 94 & 66 & 44 & 40 \\
\hline 1.5 & 48 & 216 & 474 & 672 & 716 & 652 & 548 & 444 & 356 & 284 & 228 & 180 \\
\hline 2.0 & 106 & 482 & 1050 & 1460 & 1538 & 1418 & 1210 & 986 & 794 & 634 & 508 & 350 \\
\hline 2.5 & 190 & 854 & 1742 & 2232 & 2340 & 2212 & 1938 & 1668 & 1376 & 1116 & 898 & 646 \\
\hline 3.0 & & 1300 & 2516 & 2940 & 2900 & 2934 & 2598 & 2272 & 1936 & 1652 & 1376 & 964 \\
\hline 3.5 & & & 2900 & 3000 & 3000 & 3000 & 2920 & 2888 & 2506 & 2142 & 1834 & 1300 \\
\hline 4.0 & & & & 3000 & 3000 & 3000 & 3000 & 3000 & 2900 & 2640 & 2350 & 1730 \\
\hline 4.5 & & & & & 3000 & 3000 & 3000 & 3000 & 2940 & 2700 & 2460 & 1906 \\
\hline 5.0 & & & & & & 3000 & 3000 & 3000 & 3000 & 3000 & 2740 & 2134 \\
\hline 5.5 & & & & & & & 3000 & 3000 & 3000 & 3000 & 2840 & 2470 \\
\hline 6.0 & & & & & & & & 3000 & 3000 & 3000 & 2940 & 2734 \\
\hline
\end{tabular}


Table 2

Power matrix of a WEC in terms of efficiency (\%).

\begin{tabular}{|c|c|c|c|c|c|c|c|c|c|c|c|c|}
\hline$H_{\mathrm{mo}}$ vs $T_{\mathrm{e}}$ & 5.0 & 6.0 & 7.0 & 8.0 & 9.0 & 10.0 & 11.0 & 12.0 & 13.0 & 14.0 & 15.0 & 16.0 \\
\hline 0.5 & 70.5 & 69.0 & 66.6 & 60.0 & 54.4 & 50.5 & 46.4 & 43.1 & 39.5 & 37.3 & 32.4 & 30.9 \\
\hline 1.5 & & 69.0 & 66.6 & 60.0 & 54.4 & 50.5 & 46.4 & 43.1 & 39.5 & 37.3 & 32.4 & 30.9 \\
\hline 2.5 & & & 66.6 & 60.0 & 54.4 & 50.5 & 46.4 & 43.1 & 39.5 & 37.3 & 32.4 & \\
\hline 3.5 & & & & & 54.4 & 50.5 & 46.4 & 43.1 & 39.5 & 37.3 & 32.4 & \\
\hline 4.5 & & & & & & 50.5 & 46.4 & 43.1 & 39.5 & 37.3 & 32.4 & \\
\hline 5.5 & & & & & & & & 43.1 & 39.5 & 37.3 & & \\
\hline
\end{tabular}

selected converter (they have to be combined), which means that the resolution of the deepwater characterization on which they are based should be also of the same level. Based on the information provided by the different wave energy device developers [20,21] the selected size of the energy bins are set to the highest resolution of a WEC's power matrix currently available: $0.5 \mathrm{~m}$ of $H_{\mathrm{m} 0}$ and $0.5 \mathrm{~s}$ of $T_{\mathrm{e}}$. Regards mean wave direction, in the present work intervals of $22.5^{\circ}$ are used, which bring about an accurate description of the wave resource in NW Spain [16].

Once defined the resolution of the trivariate intervals, each of the hourly sea states in the dataset is assigned to the corresponding energy bin [e.g. $H_{\mathrm{m} 0}=3-3.5 \mathrm{~m}, T_{\mathrm{e}}=9-9.5 \mathrm{~s}, \theta_{\mathrm{m}}=303.75-$ $326.25^{\circ}$, and their wave power per unit width, $J$, computed according [22],

$J=\frac{\rho g}{16} H_{\mathrm{m} 0}^{2} C_{\mathrm{g}}$

where $\rho$ is the seawater density, $g$ is the gravitational acceleration, and $C_{\mathrm{g}}$ is the group velocity, or the celerity at which wave energy is carried, which can be calculated as [23],

$C_{\mathrm{g}}=\frac{1}{2}\left(1+\frac{2 k h}{\sin h(2 k h)}\right)\left(\frac{g T}{2 \pi} \tan h(k h)\right)$

where $k$ is the wave number and $h$ the local water depth. Now, the contribution to the total resource of each energy bin and its occurrence can be computed and used to produce a 3D characterization matrix. For clarity, Fig. 3(a) shows the omnidirectional representation (2D) of the 3D characterization matrix, with $0.5 \mathrm{~m}$ intervals of $H_{\mathrm{m} 0}$ and $1 \mathrm{~s}$ of $T_{\mathrm{e}}$ (of a maximum of $0.5 \mathrm{~s}$ for clarity), with the colour plot representing the annual energy available (in MWh per meter of wave front) and the numbers, the occurrence (in hours per year) of each $H_{\mathrm{m} 0}$ and $T_{\mathrm{e}}$ combination.

\subsection{Selection and propagation of the relevant wave energy cases}

The next step in the methodology is to propagate the most representative deepwater wave cases or energy bins - those providing the bulk of the energy. Although the conventional procedure is to consider a handful of study cases, recent studies have shown the importance of considering a high percentage of the total energy $[16,17]$, which clearly will result in a more accurate estimate of the available resource and in consequence of energy production. In practice, it requires the consideration of a large number of energy bins, which means to propagate a large number of wave conditions and as a result a greater computational effort. In the present study, a sensitivity analysis (Table 3 ) is performed, showing the number of cases or energy bins that would be necessary to consider if a certain level of energy and time is to be achieved. It can be observed that, instead of propagating a great amount of cases so as to consider $100 \%$ of the available energy, the consideration of the 787 most energetic energy bins is enough to represent $95 \%$ of the resource (corresponding to $88.7 \%$ of the time). However, the consideration of a lower level of energy would not reduce significantly the number
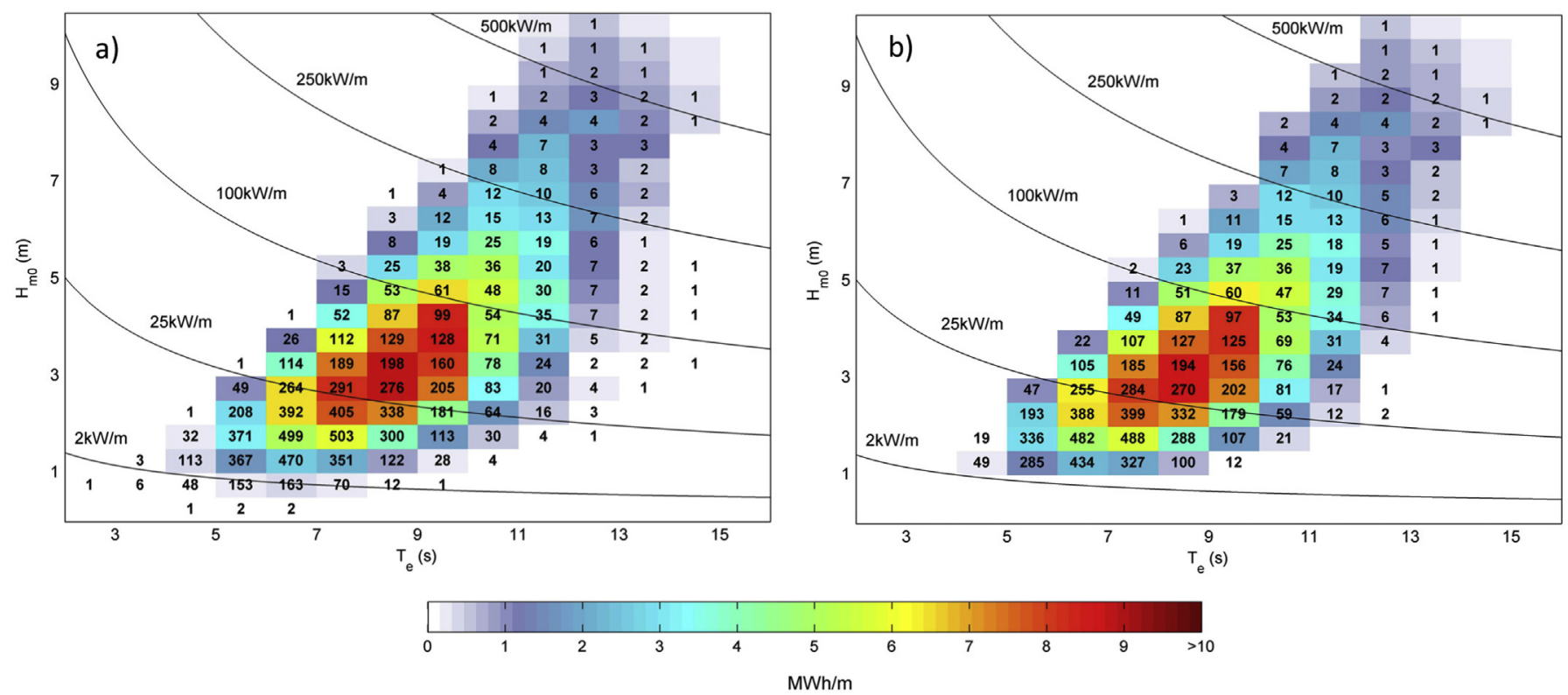

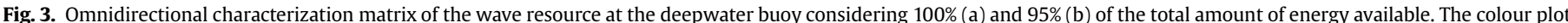

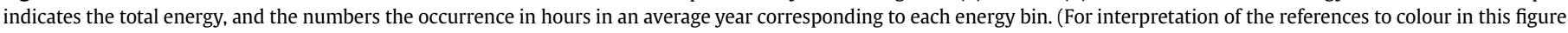
legend, the reader is referred to the web version of this article.) 
Table 3

Sensitivity analysis (percentage of the total annual energy, \% Energy, and percentage of the total annual time, \% Time).

\begin{tabular}{lcc}
\hline Number of energy bins & \% Energy & \% Time \\
\hline 182 & 50 & 42.8 \\
381 & 75 & 66.8 \\
622 & 90 & 83.5 \\
787 & 95 & 88.7 \\
1554 & 100 & 100 \\
\hline
\end{tabular}

of cases to be propagated. The representation of the omnidirectional characterization matrix corresponding to $95 \%$ of energy (Fig. 3(b)) shows that the remaining 5\% is mostly composed of two types of sea states: i) very low energetic sea states due to reduced wave heights and periods (sea states of under $1 \mathrm{~m}$ of $H_{\mathrm{m} 0}$ are not considered) and ii) very powerful sea states with very low occurrence (extreme conditions). In both conditions, WECs do not operate; in the first case, they cannot operate due to the reduced wave height (Tables 1 and 2), and in the second case, WECs stop working to protect themselves (survival mode). This means that $95 \%$ of energy virtually represents $100 \%$ of the exploitable resource. Nevertheless, the consideration of a lower level of energy, may lead to not taking into account a large number of wave cases during which the WEC would operate. On this basis, the number of cases corresponding to $95 \%$ of energy of the total resource is retained in this work.

To propagate the selected wave conditions there is used the spectral model SWAN (Simulation WAves Nearshore) [24], which computes the evolution of the wave spectrum by solving the action balance equation. For this purpose a high-resolution grid is constructed (Fig. 4). The area covered by the grid is determined according to two prerequisites: i) the offshore boundary is located so deep that transformation processes have not yet influenced the wave field (deepwater condition) and ii) the lateral boundaries are distant enough so that any disturbance that may exist along them, cannot reach the region of interest.

The grid has a varying size decreasing from the deepwater contours towards approximately a $120 \mathrm{~m}$ water depth, the maximum depth at which offshore devices are expected to be deployed (and therefore the area of interest for wave energy exploitation). A key aspect to take into account is the fact that a strong variation in the available energy may exist in short distances (over a scale of hundreds of meters or even less), arising from a sudden variation of water depth. In other words, the characterization matrices within the coastal region may greatly differ over short distances. This variation should be properly modelled, for which the implementation of a high resolution grid is required. After a thorough analysis of the bathymetry of the area of study (Fig. 5) and considering previous wave energy studies in the region [19], the grid size in the area of interest (of under a depth of $120 \mathrm{~m}$ ) is set to $200 \mathrm{~m}$, much finer than that normally used following a conventional procedure. This results in a total number of grid nodes of 69,847 .

Prior to propagating the selected energy bins, the model is validated by comparing the numerical results and buoy records. For this purpose, the model is forced with deepwater conditions recorded by the Vilán-Sisargas buoy covering a 14-day period (halfmonth), from 1.2.2011 to 15.2.2011, and the results compared with

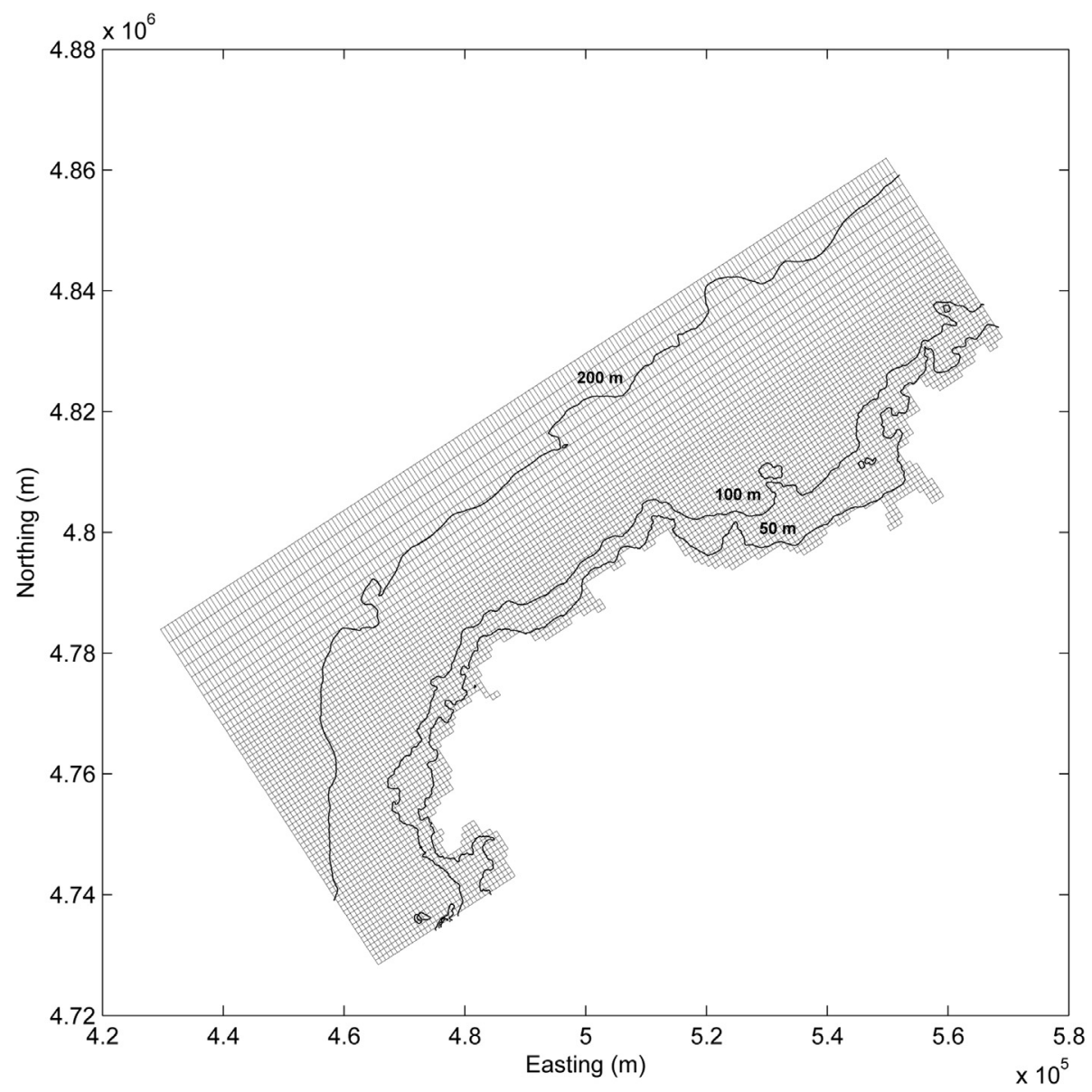

Fig. 4. High resolution grid for the spectral numerical model. For clarity, only one in three coordinate lines are shown. 


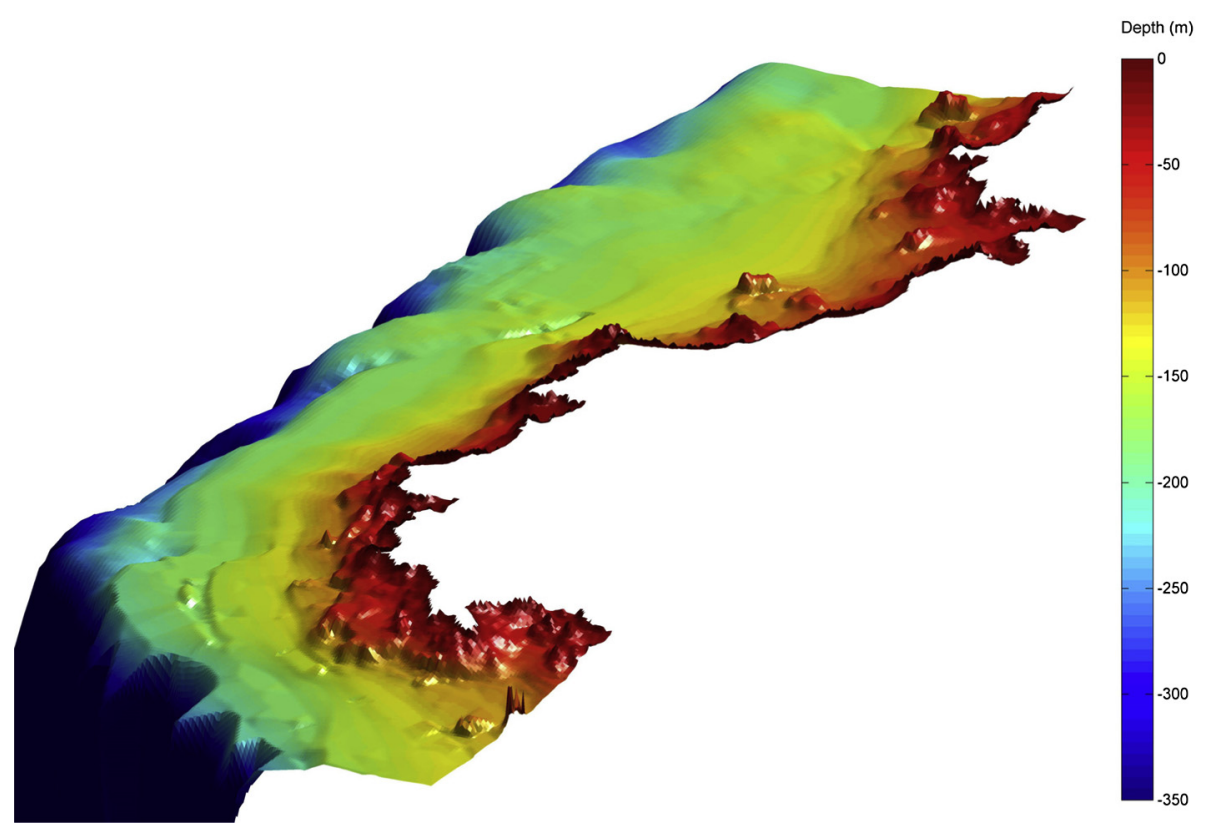

Fig. 5. 3D bathymetry of the Death Coast region.

hourly sea state records provided by a coastal buoy located at a $60 \mathrm{~m}$ water depth (Fig. 1). This period is selected insofar as it considers the whole range of wave conditions that a WEC can harness, including very powerful sea states. Excellent agreement is found between computational results and measurements (Fig. 6), obtaining a correlation coefficient of $R=0.924$ and $R=0.917$ for wave height and wave power, respectively.

Once validated the numerical model, the selected wave cases (787 energy bins) are propagated towards the coast. The wave conditions prescribed at the open ocean boundary representing each energy bin are set to those providing the average energy of the corresponding bin and the remaining spectral parameters defined following previous wave resource studies in the region [16]. For instance, in the case of the energy bin $\left[H_{\mathrm{m} 0}=3-3.5 \mathrm{~m}, T_{\mathrm{e}}=9-9.5 \mathrm{~s}\right.$, $\theta_{\mathrm{m}}=303.75-326.25^{\circ} \mathrm{]}$, the parameters propagated are: $H_{\mathrm{m} 0}=3.269 \mathrm{~m}, T_{\mathrm{e}}=9.25 \mathrm{~s}, \theta_{\mathrm{m}}=315^{\circ}$.

\subsection{Wave energy resource at a particular location}

This step of the methodology consists in obtaining the modified wave parameters at any site within the Death Coast (grid nodes of the computational domain) with a view to provide the elements allowing the computation of energy production. For this purpose, after running the model, the spectral parameters $H_{\mathrm{m} 0}, T_{\mathrm{e}}$, and $\theta_{\mathrm{m}}$ at each grid node are obtained for each wave condition propagated and the wave power is computed according to [25]:

$J=\rho g \int_{0}^{2 \pi} \int_{0}^{\infty} S(f, \theta) C_{\mathrm{g}}(f, h) d f d \theta$.

Subsequently, the energy associated with each wave field is obtained from its wave power and their probability of occurrence
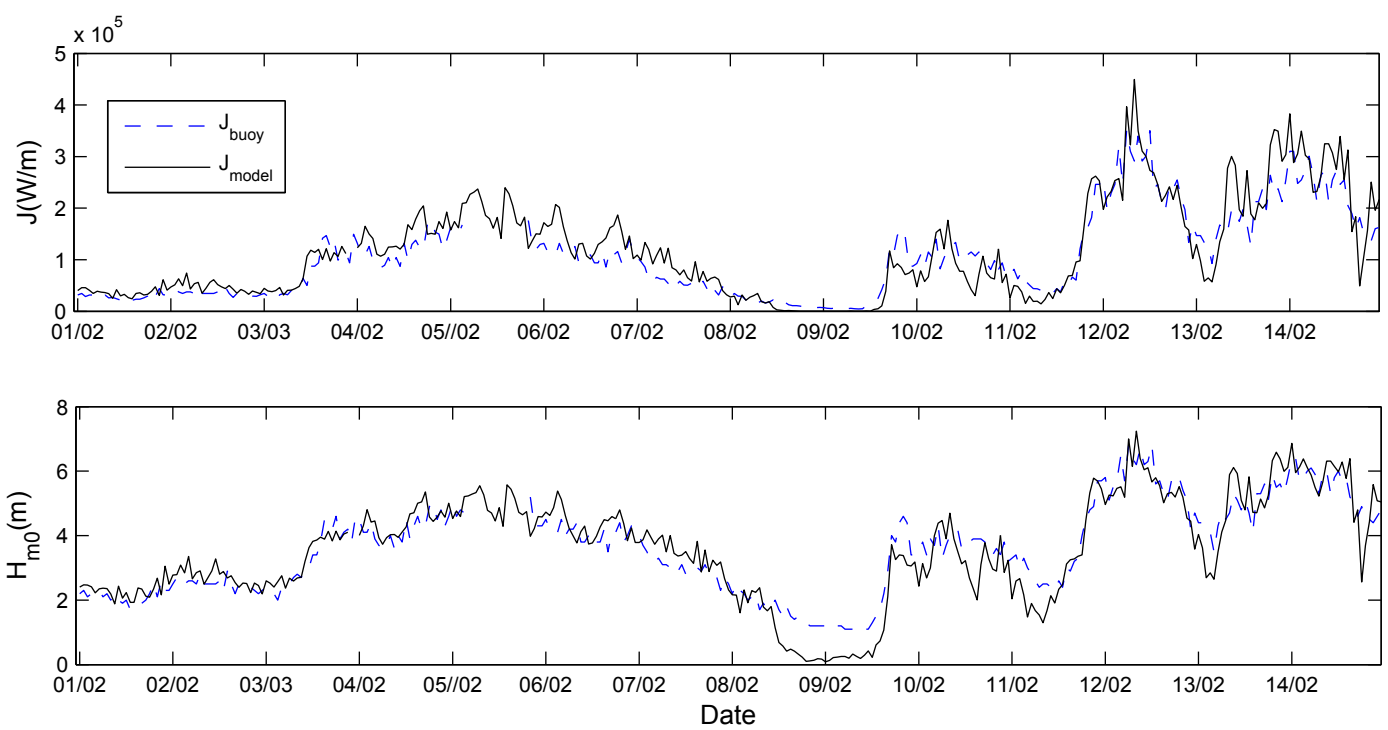

Fig. 6. Wave power (above) and spectral wave height (below) computed by the numerical model and recorded at the coastal buoy location. 
from the characterization of the deepwater wave resource (although the wave field is transformed as it propagates from deepwater to the shore, its probability of occurrence is conserved). As a result, the same spectral parameters of interest at the deepwater buoy are now available at any point of the computational grid. Therefore, the wave resource at any location within this region can be reconstructed in the form of a characterization matrix (with the same resolution of energy bins as the deepwater characterization, and spatial resolution as the computational grid), following the same procedure explained in Section 2.1.

\subsection{A Matlab-based toolbox for characterization matrix generation}

The final step of this work is to develop a toolbox capable of reading the information stored in the database, and automatically reconstructing the wave energy resource, in terms of an energy diagram or characterization matrix with the appropriate resolution at any point within the Death Coast. Therefore, any device developer, policy maker, researcher or stakeholder will be able to easily compute the energy production of any WEC at any location of interest.

For this purpose, it would be enough to compute and store the figures corresponding to the total energy available and the number of hours of occurrence of each energy bin at each grid node (the information included in the characterization matrix) and then develop a programme to handle this information. The problem lies in the fact that the storage of 69,847 characterization matrices (number of grid nodes) represents an enormous amount of data to be stored (it would occupy a great part of a personal computer hard disk) which, in addition, would considerably slow down (or even impede) the functioning of the programme. With this in view, a set of programmes written in MATLAB, which can directly read the information resulting from the 787 numerical propagations and automatically reconstruct (in real time) the characterization matrices, was developed without the need for storing a huge amount of data. The result is the toolbox WEDGE (Wave Energy Diagram GEnerator), a package of routines which works as follows. First, the toolbox is invoked by typing WEDGE in the Matlab Command Window (Fig. 7). Then, the user is asked to define the resolution of the energy bins of the characterization matrix (obviously, the maximum resolution available is $H_{\mathrm{m} 0}=0.5 \mathrm{~m}, T_{\mathrm{e}}=0.5 \mathrm{~s}$ in case of considering an omnidirectional matrix), which should be of the same level as that of the power matrix of the device used for energy production computations. Next, the toolbox asks for the location of interest where the characterization matrix is to be computed. This can be done in two different ways: i) by introducing manually the spatial coordinates or ii) by using a GUI (graphical user interface) specially designed for this purpose. If the user

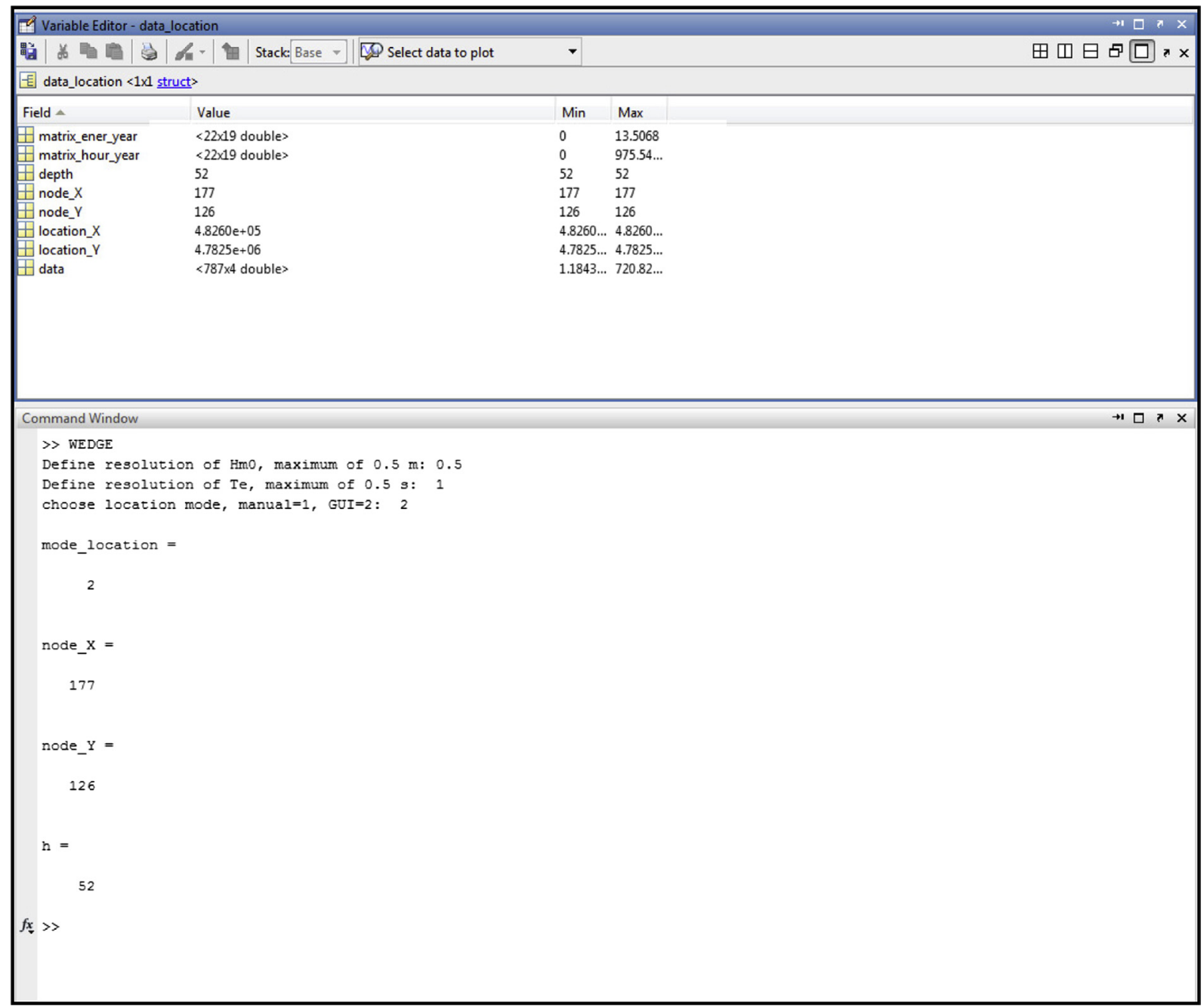

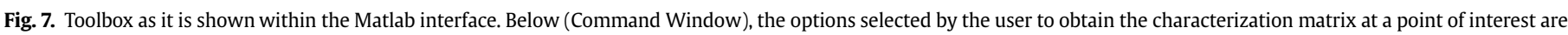
shown; above (Variable Editor), the data contained in the variable data_location_interest are also shown. 


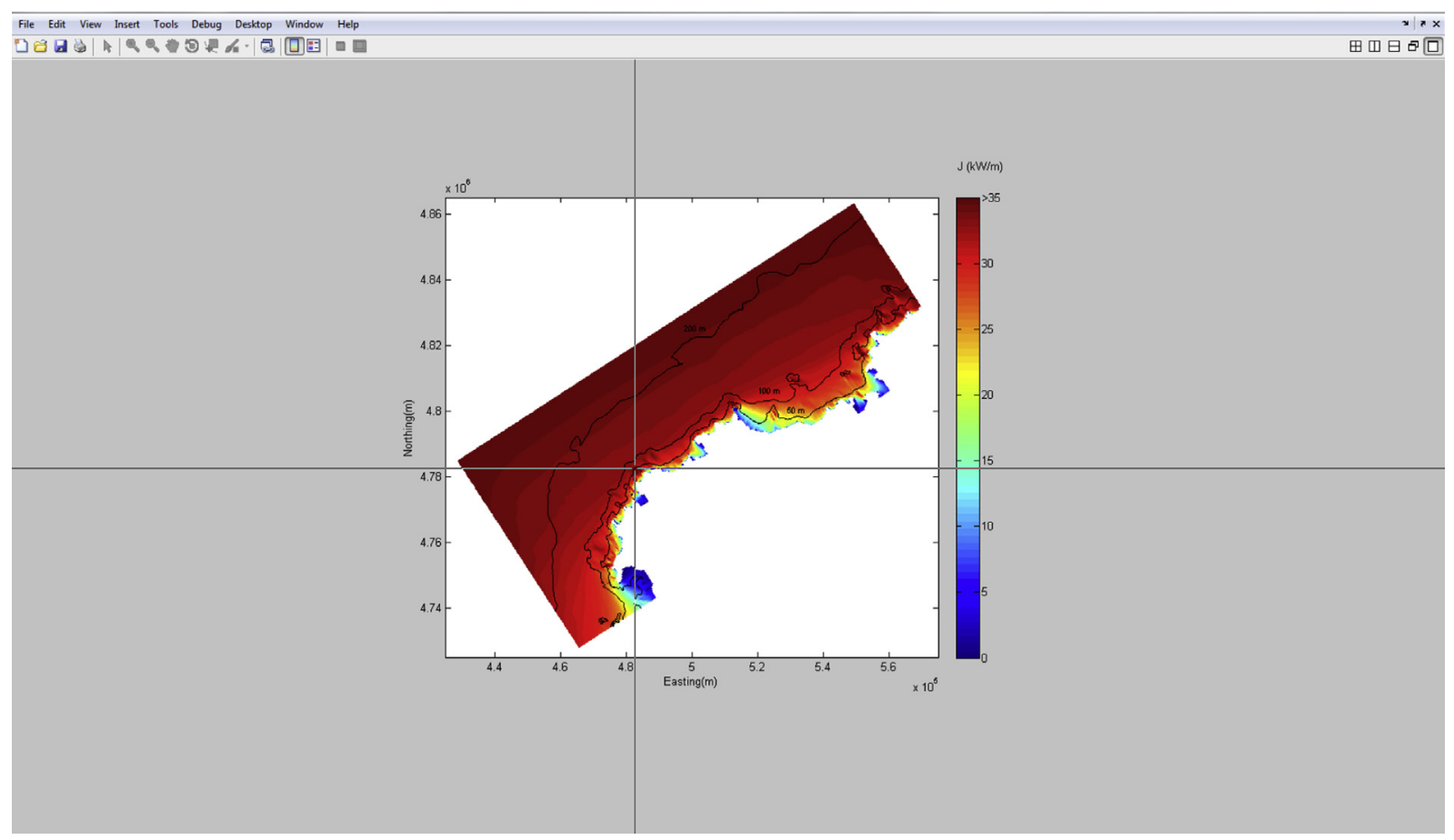

Fig. 8. GUI for selecting a point of interest where the characterization matrix is to be computed.

chooses the second option, a map of the average power available including the bathymetric isolines is automatically plotted on which a pointer is available for the interactive selection of the desired location (Fig. 8). When the user defines a location, the code finds the closest grid node (node_X and node_Y in Fig. 7). Afterwards, the information at this node corresponding to the spectral parameters stored resulting from the 787 wave cases propagated, as well as the number of annual hours of occurrence of each wave case, are read and used by the toolbox to reconstruct the corresponding energy diagram (characterization matrix) with the appropriate resolution (Fig. 9). As stated before, the computations are performed in real time, a process which only takes a few seconds. The total energy and the number of hours of occurrence corresponding to each energy bin of the characterization matrix (matrix_ener_year and matrix_hour_year variables, respectively), together with other data of interest are automatically stored within the structured variable data_location (Fig. 7). Thereby, the user can select the required information for energy production calculations depending on the characteristics of the device's power matrix (Table 1 or 2 ).

It is important to note that the energy bins of the characterization matrix showed (Fig. 9) correspond with a bivariate distribution of the $H_{\mathrm{m} 0}$ and $T_{\mathrm{e}}$ in which the $\theta_{\mathrm{m}}$ is neglected (omnidirectional matrix). This stems from the fact that, as stated in Section 2.1, the power matrices currently provided by device developers - with which the characterization matrices have to be combined in order to compute the energy production - are also omnidirectional. Nevertheless, the wave direction is taken into account throughout the development of the database; in particular, the numerical model computes the modification of the wave direction of each energy bin in their propagation from deepwater towards the coast, and the results are stored within the database together with the remaining spectral parameters. Thus, the user can use the database to generate 3D characterization matrices (including wave direction), if the information related to the variation of the WEC's performance with the variation in wave direction is provided in the future.
Finally, some regions of interest for wave energy exploitation have been shown to exhibit a significant seasonal or even monthly wave climate variability [26-31]. In this case, in addition to the total energy production, intra-annual wave resource information should be analysed for computing other parameters of interest providing relevant information for the proper configuration of WECs (e.g. installed capacity) [16].

\section{Case study}

The interest of the present database, as previously explained, lies in two facts. In first place it has been shown in Section 2 the need for describing the resource in the form of a characterization matrix with the appropriate resolution of energy bins, given that

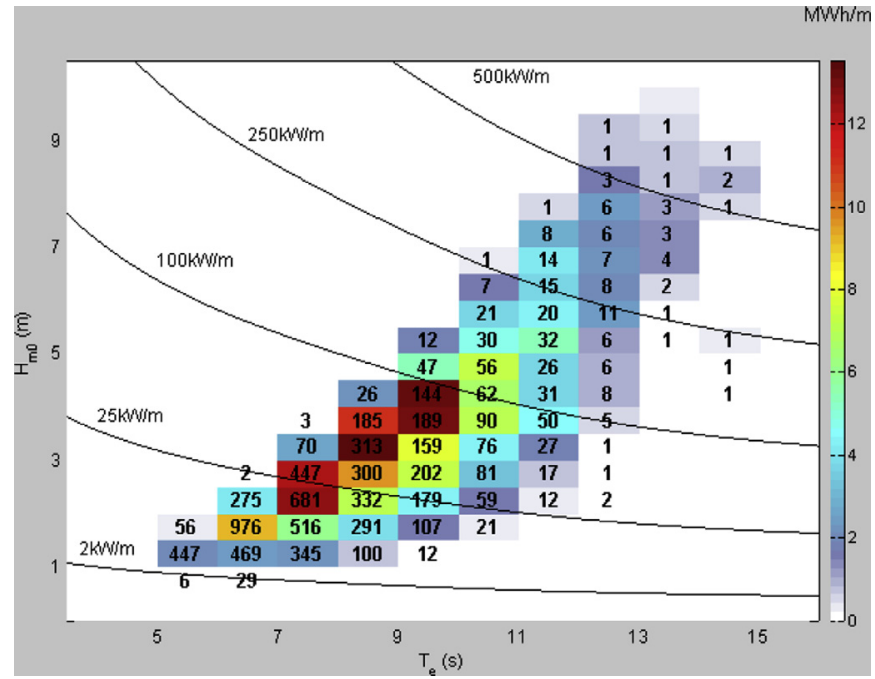

Fig. 9. Characterization matrix automatically generated at the location selected with the GUI in Fig. 8 . 


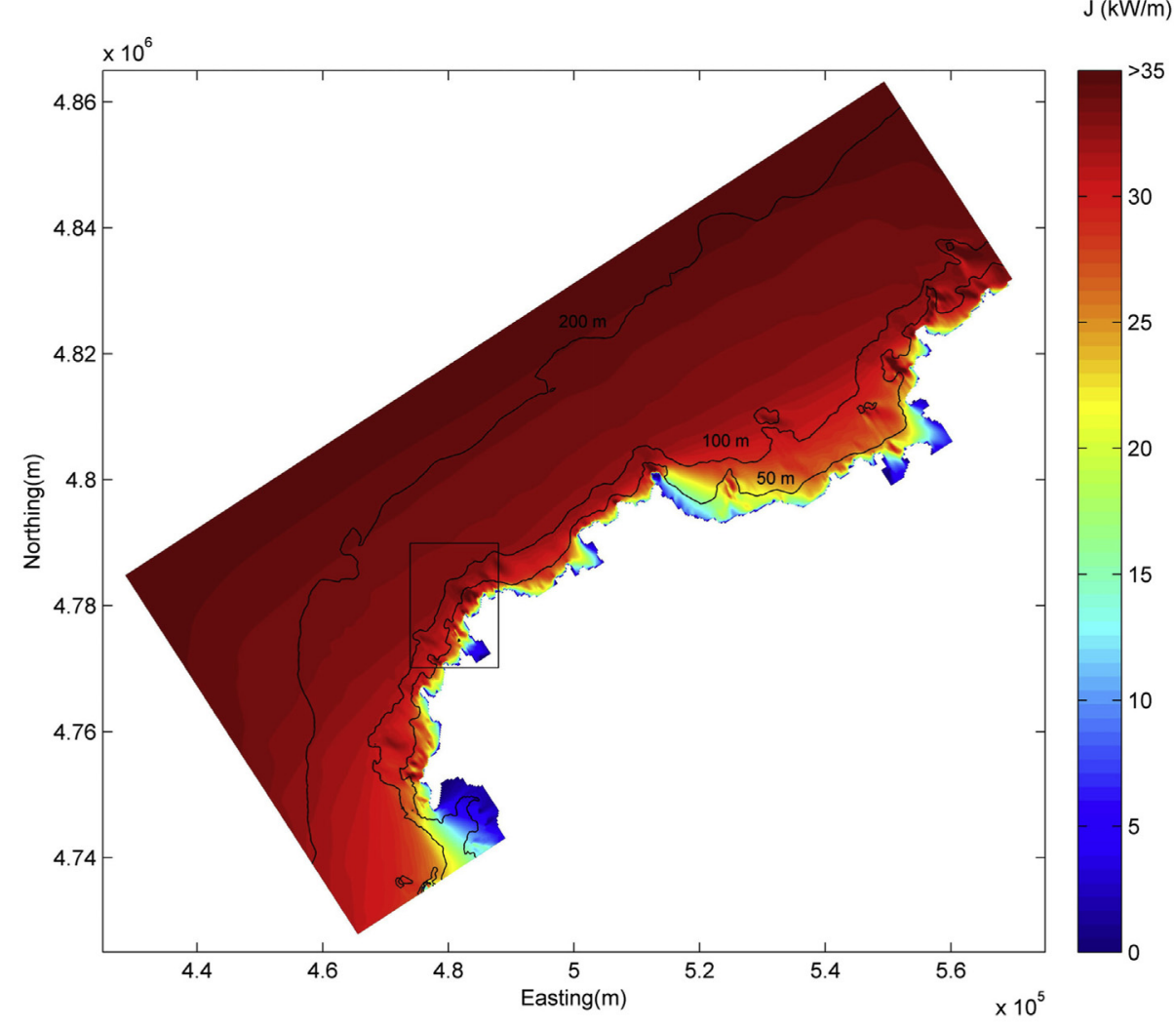

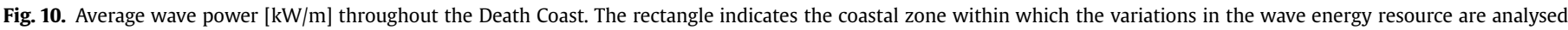
(Fig. 11).

the WEC's power matrix with which it has to be combined has also a specific bin resolution. The current lack of this information is solved for the Death Coast by means of the present database, which is capable of generating characterization matrices with the same resolution as the maximum resolution of the WECs' power matrices. In second place, the irregular bathymetry of some areas may cause abrupt changes in the spatial distribution of the resource, and therefore the characterization matrices within the coastal region may greatly differ in short distances. Thus, this resource variability should be properly described for accurate wave energy production computations.

In this section, the importance of the spatial resolution provided by the present database for properly describing the spatial variability of the wave energy resource, is analysed through a case study. The available wave power in this region has been previously studied, and several hot spots identified and proposed as possible areas for wave energy exploitation [18]. One of these areas is of special interest, due to its being located next to two harbours (Fig. 1), and thus selected for further analysis with the database.

Prior to this work, the only data available for energy production computations in this region were those corresponding to the SIMAR-44 dataset (black circles in Fig. 1) (in addition to buoy data), composed of hindcast wave data covering a 44-year period (19582001) with a 3-h frequency. These dataset were obtained using the WAM third generation spectral model forced with wind fields provided by the REMO atmospheric model within the HIPOCAS project [32] which in turn was forced with data resulting from global atmospheric reanalysis computed by the U.S. National Center for Environmental Prediction. Despite their constituting a set of data with valuable information regarding the wave climate, it may occur that they do not provide accuracy when computing the energy a WEC would produce at a specific coastal location of interest. In the present case study, the closest SIMAR point to the proposed area for wave energy exploitation (Fig. 1) is located at a distance of more than $20 \mathrm{~km}$ and, more importantly, at an utterly different depth. Therefore, the resource provided by SIMAR point is expected to be quite different from that within the area of interest, which in turn would lead to significant inaccuracies when computing the energy production in the proposed area, should SIMAR characterization matrix be used for this purpose. In addition, SIMAR dataset does not provide information related to the $T_{\mathrm{e}}$; instead, the peak period, $T_{\mathrm{p}}$ has to be transformed into $T_{\mathrm{e}}$ assuming a specific spectrum, leading to a less precise estimation of the energy contained in each energy bin.

In order to accurately define the deviation of the wave resource between the closest SIMAR point and within the area proposed for a wave farm, the characterization matrices at SIMAR location and at three locations within the area of interest are compared (Figs. 10 and 11). In the case of the SIMAR point the characterization matrix (Fig. 12) is computed assuming that $T_{\mathrm{e}}=0.9 T_{\mathrm{p}}$ following previous studies [16]. In addition, it has been stated that in areas with irregular bathymetry, as it is the case, changes in the available wave energy resource could exist over scales of hundreds of meters or even less, meaning that the energy that could be produced at different locations within the proposed area could greatly differ. On this basis the three locations selected $(A, B, C)$ are separated by a distance of less than $500 \mathrm{~m}$ (Fig. 11) and their characterization matrices computed by means of the database (Fig. 13). For clarity and comparison purposes, the resolution of the energy bins is set to $H_{\mathrm{m} 0}=0.5 \mathrm{~m}$ and $T_{\mathrm{e}}=1 \mathrm{~s}$ ( of a maximum of $T_{\mathrm{e}}=0.5 \mathrm{~s}$ ).

It can be observed that there exist quite important differences between the wave energy resource at the SIMAR point and the 


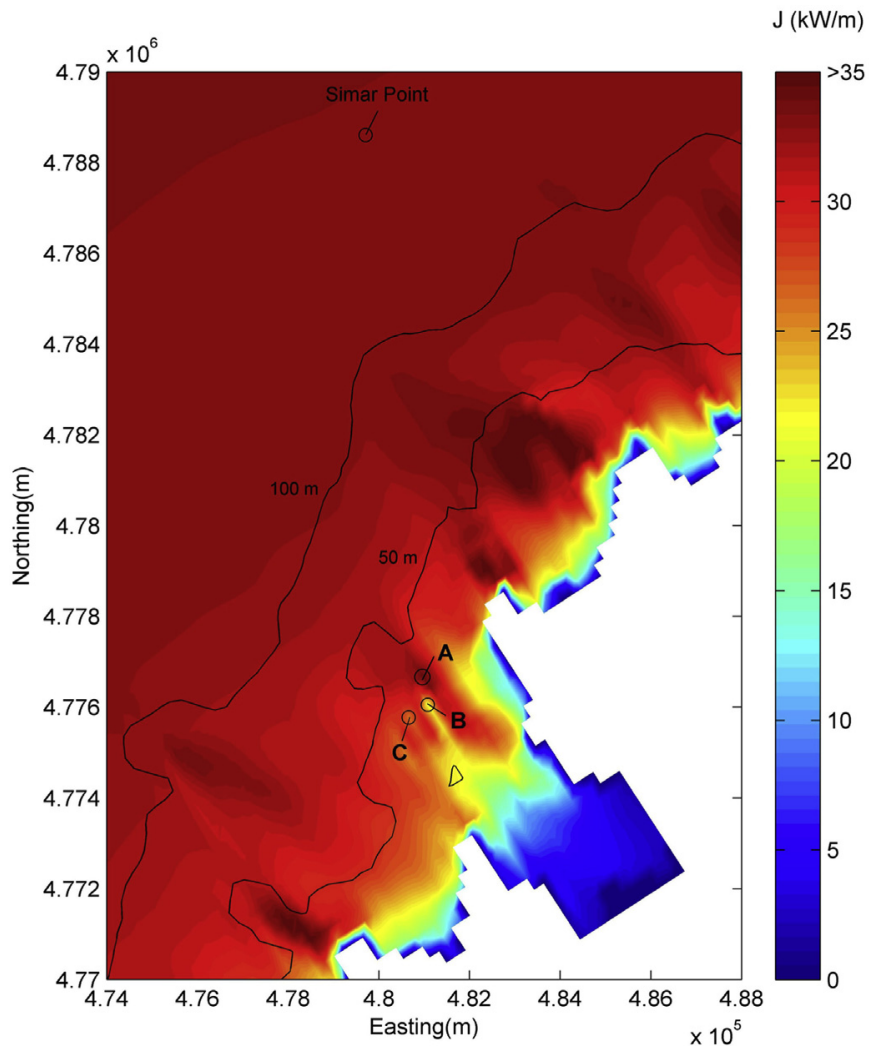

Fig. 11. Average wave power map of the coastal zone marked in Fig. 10 with the locations (A, B, C and SIMAR) at which the characterization matrices are reconstructed.

proposed area, as it could be expected for the distance and different depth. In addition, when comparing the characterization matrices at the three points $(A, B, C)$ within the area of interest, significant deviations, although of less importance, are again observed. The major difference consists in that, whereas at point A the bulk of the energy is distributed over a wide range of $H_{\mathrm{m} 0}$ and $T_{\mathrm{e}}$, at points $\mathrm{C}$ and especially $\mathrm{B}$, it is concentrated within a reduced number of energy bins. Obviously, the significant dissimilarities in the resource will lead to significant deviations in the estimation of the actual energy a WEC would produce.

\section{Conclusions}

A correct decision-making regarding wave energy exploitation should be based on an accurate knowledge of the different factors affecting its exploitation. Amongst them, the estimation of energy production of a WEC at a location of interest is of key importance. In this paper, a comprehensive procedure, far from the conventional approach, is implemented in the Death Coast (NW Spain) with the aim of developing a geospatial database of the wave energy resource providing the required information for conducting this estimation with accuracy and reliability throughout this region.

First, the deepwater wave energy resource is characterized based on a large dataset of spectral buoy records and following the energy bin concept, or trivariate intervals of significant wave height, energy period and mean wave direction. Furthermore, in contrast with the conventional approach which considers only a handful of study cases and a limited resolution of the energy bins, this work covers 95\% of the total energy (which in practice represents virtually $100 \%$ of the exploitable resource) with a resolution of $0.5 \mathrm{~m}$ of wave height, $0.5 \mathrm{~m}$ of period and $22.5^{\circ}$ of wave direction. This resolution is shown to be enough to characterize the resource with a view to energy production calculations. Next, a high resolution numerical model (grid spacing of $200 \mathrm{~m}$ ) is implemented and a total of 787 wave cases (those corresponding to $95 \%$ energy level) are propagated.

Finally, a Matlab-based toolbox called WEDGE capable of accessing the database and of reconstructing the wave energy resource at any point in the Death Coast is implemented. It allows the selection of any location (resolution of $200 \mathrm{~m}$ ) and the computation of its characterization matrix with the aforementioned size of energy bins. Once computed the matrix, the relevant

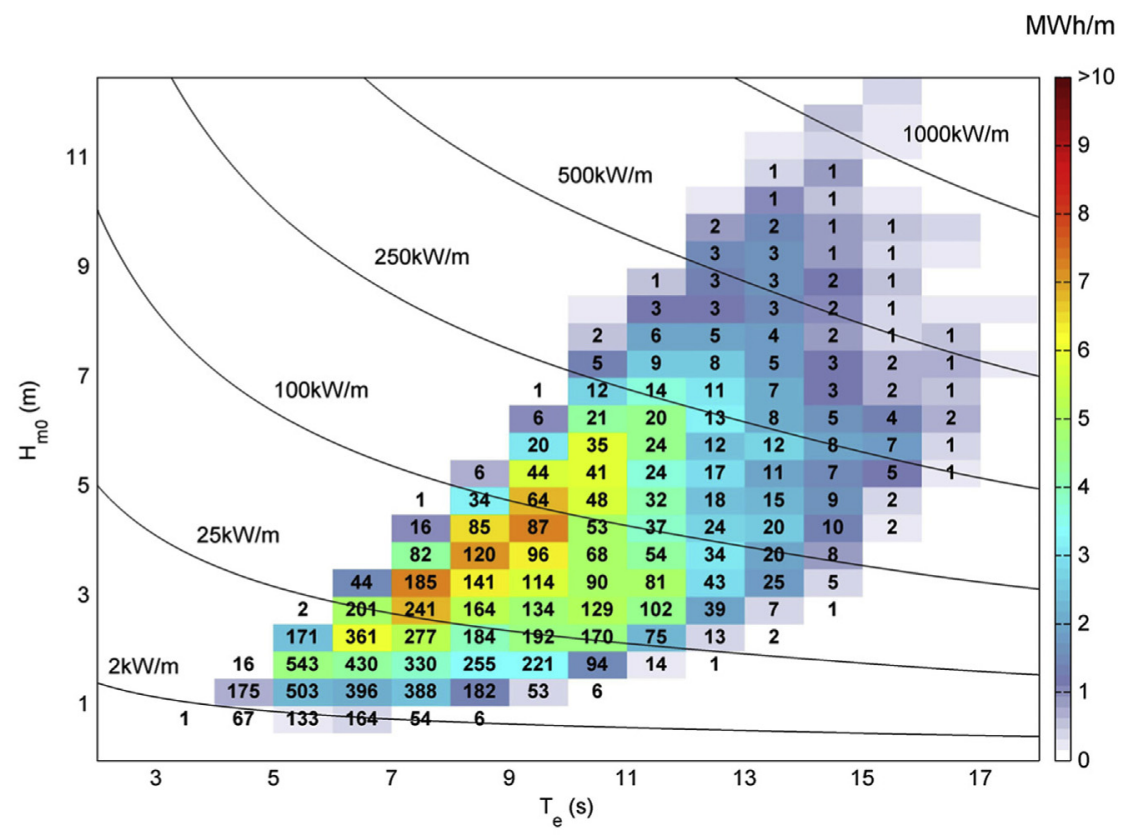

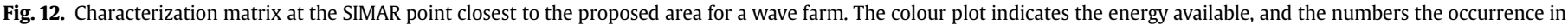

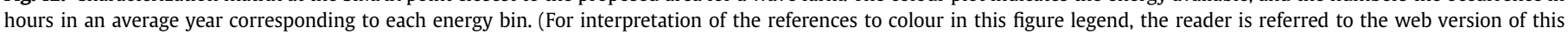
article.) 

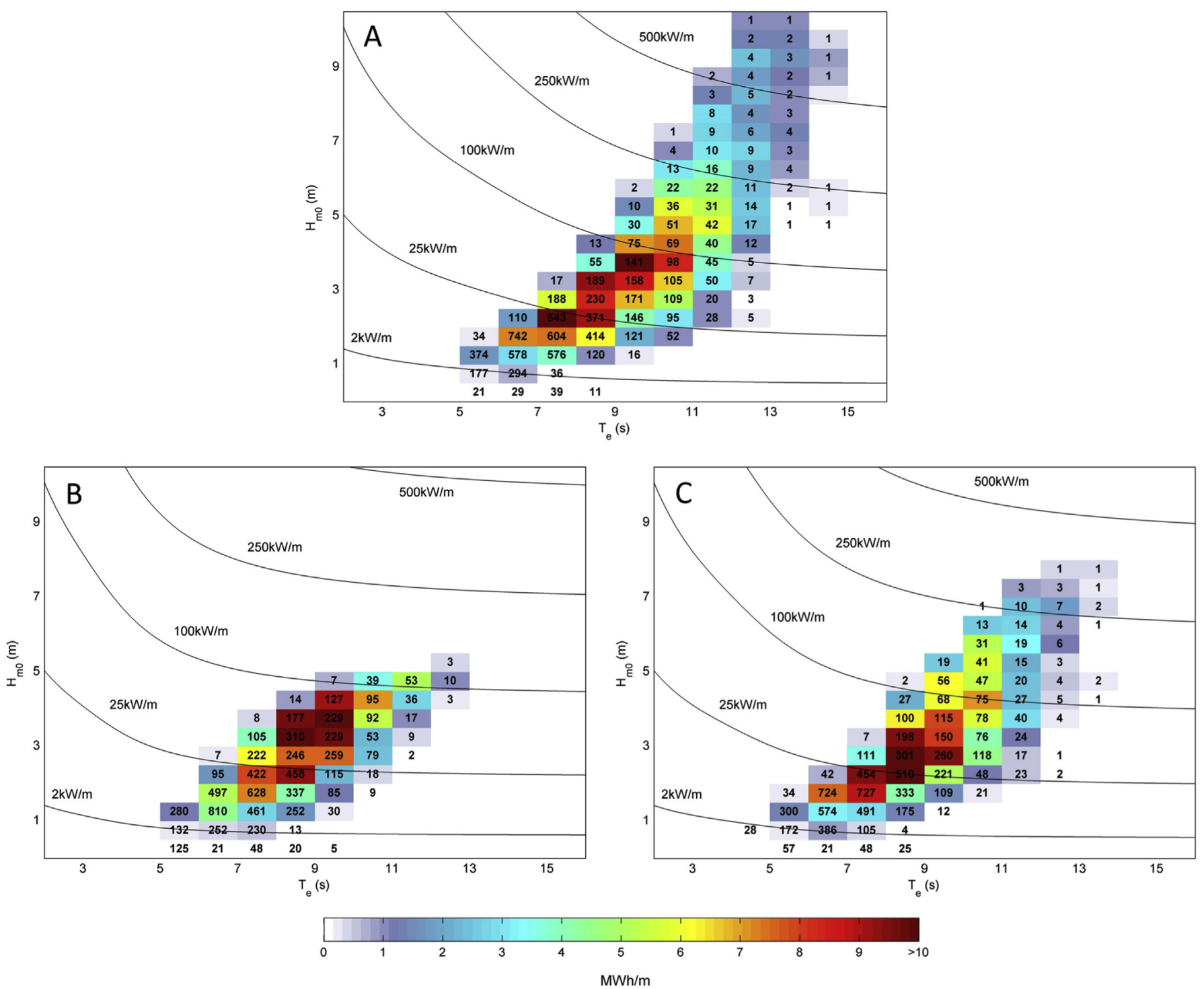

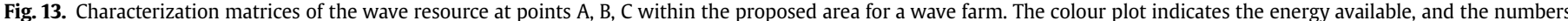

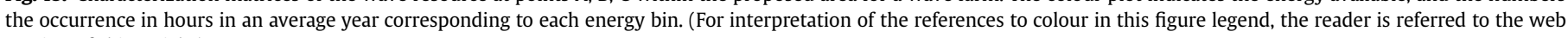
version of this article.)

information is automatically stored and thereby, it suffices to combine it with the corresponding information contained in the WEC's power matrix to determine the energy production at the desired location.

The interest of this database, and in particular of the spatial resolution provided, is further investigated by means of a case study, a recently proposed wave farm in the Death Coast. Several wave characterization matrices are generated and compared: i) a characterization matrix at the SIMAR point closest to the proposed area for the wave farm, which is at a distance of more than $20 \mathrm{~km}$ (the only wave resource dataset available prior to the present work), and ii) three characterization matrices at three different locations within the proposed area, separated by less than $500 \mathrm{~m}$. It is shown that, first, in the present case study SIMAR dataset are not valid for energy production computations and further information is necessary, and second, a high resolution spatial database (more than $500 \mathrm{~m}$ ) is required in such regions of irregular bathymetry as the Death Coast.

In summary, in this work there is developed a database of the wave energy resource throughout the Death Coast, NW Spain. The database allows the generation of high resolution characterization matrices at any coastal site and thus providing accuracy and reliability in the computation of the energy that any WEC would produce at any location of interest. Although the present database is currently only available for this region, the procedure developed in this work could be used to produce a database in any other coastal region in which long-term deepwater data are available.

In future work, the database will be extended so as to produce additional information of interest for wave energy exploitation. In particular, it will be extended in order to compute intra-annual characterization matrices providing relevant information for the proper configuration of a WEC at a specific location of interest.

\section{Acknowledgements}

This work has been conducted in the framework of the project Development of a Geospatial Database of the Exploitation of the Wave Energy Resource along the Galician Coast supported by the Barrié Foundation and the project DPI2009-14546-C02-02 Assessment of 
Renewable Energy Resources of the Spanish Ministry of Science and Innovation.

\section{List of symbols}

\begin{tabular}{|c|c|}
\hline$H_{\mathrm{m} 0}$ & significant wave height [m] \\
\hline$T_{\mathrm{e}}$ & energy period [s] \\
\hline$\theta_{\mathrm{m}}$ & mean wave direction $\left[{ }^{\circ}\right]$ \\
\hline$m_{\mathrm{n}}$ & $n$-th spectral moment $\left[\mathrm{m}^{2} \mathrm{~Hz}^{-n}\right]$ \\
\hline$S$ & spectral density $\left[\mathrm{m}^{2} \mathrm{~Hz}^{-1}\right]$ \\
\hline$\theta$ & wave direction $\left[{ }^{\circ}\right.$ ] \\
\hline$f$ & wave frequency [Hz] \\
\hline$J$ & wave power per unit width $\left[\mathrm{kWm}^{-1}\right]$ \\
\hline$\rho$ & seawater density $\left[\mathrm{kgm}^{-3}\right]$ \\
\hline$g$ & gravitational acceleration $\left[\mathrm{ms}^{-2}\right]$ \\
\hline$C_{g}$ & group velocity $\left[\mathrm{ms}^{-1}\right]$ \\
\hline$k$ & wave number $\left[\mathrm{m}^{-1}\right]$ \\
\hline$h$ & local water depth [m] \\
\hline$T_{\mathrm{p}}$ & peak period $[s]$ \\
\hline
\end{tabular}

\section{References}

[1] Bahaj AS. 8.01-Generating electrical power from ocean resources. In: Sayigh Ali, editor. Comprehensive renewable energy. Oxford: Elsevier; 2012. pp. 1-6.

[2] Lund H. Renewable energy strategies for sustainable development. Energy 2007;32(6):912-9.

[3] Falcão AFdO. Wave energy utilization: a review of the technologies. Renew Sustain Energy Rev 2010;14(3):899-918.

[4] Lopes MFP, Hals J, Gomes RPF, Moan T, Gato LMC, Falcão AFdO. Experimental and numerical investigation of non-predictive phase-control strategies for a point-absorbing wave energy converter. Ocean Eng 2009;36(5):386-402.

[5] Fernandez H, Iglesias G, Carballo R, Castro A, Fraguela JA, Taveira-Pinto F, et al The new wave energy converter WaveCat: concept and laboratory tests. Mar Struct 2012;29:58-70.

[6] Cruz JMBP, Sarmento AJNA. Sea state characterisation of the test site of an offshore wave energy plant. Ocean Eng 2007;34(5-6):763-75.

[7] Caska AJ, Finnigan TD. Hydrodynamic characteristics of a cylindrical bottompivoted wave energy absorber. Ocean Eng 2008;35(1):6-16.

[8] Smith HCM, Haverson D, Smith GH. A wave energy resource assessment case study: review, analysis and lessons learnt. Renew Energy 2013;60(0):510-21.

[9] Iglesias G, Carballo R. Wave energy and nearshore hot spots: the case of the SE Bay of Biscay. Renew Energy 2010;35(11):2490-500.

[10] Iglesias G, Carballo R. Wave energy resource in the Estaca de Bares area (Spain). Renew Energy 2010;35(7):1574-84.
[11] Akpinar A, Kömürcü MI. Wave energy potential along the south-east coasts of the Black Sea. Energy 2012;42:289.

[12] Akpınar A. Kömürcü Mí. Assessment of wave energy resource of the Black Sea based on 15-year numerical hindcast data. Appl Energy 2013;101(0):502-12.

[13] Rusu L, Guedes Soares C. Wave energy assessments in the Azores islands. Renew Energy 2012:45:183-96.

[14] Rusu E, Guedes Soares C. Wave energy pattern around the Madeira Islands. Energy 2012;45(1):771-85.

[15] Lenee-Bluhm P, Paasch R, Özkan-Haller HT. Characterizing the wave energy resource of the US Pacific Northwest. Renew Energy 2011;36(8):2106-19.

[16] Carballo R, Iglesias G. A methodology to determine the power performance of wave energy converters at a particular coastal location. Energy Convers Manag 2012;61(0):8-18.

[17] Iglesias G, Carballo R. Choosing the site for the first wave farm in a region: a case study in the Galician Southwest (Spain). Energy 2011;36(9):5525-31.

[18] Iglesias G, Carballo R. Wave energy potential along the Death Coast (Spain). Energy 2009;34(11):1963-75.

[19] Carballo R, Iglesias G. Wave farm impact based on realistic wave-WEC interaction. Energy 2013;51(0):216-29.

[20] The Carbon Trust. Oscillating water column wave energy converter evaluation report. Arup Energy (for Carbon Trust); 2005.

[21] Babarit A, Hals J, Muliawan MJ, Kurniawan A, Moan T, Krokstad J. Numerical benchmarking study of a selection of wave energy converters. Renew Energy 2012;41:44-63.

[22] Iglesias G, López M, Carballo R, Castro A, Fraguela JA, Frigaard P. Wave energy potential in Galicia (NW Spain). Renew Energy 2009;34(11):2323-33.

[23] Dean RG, Dalrymple RA. Water wave mechanics for engineers and scientists. World Scientific; 1991

[24] Booij N, Ris RC, Holthuijsen LH. A third-generation wave model for coastal regions 1. Model description and validation. J Geophys Res C Oceans 1999;104(C4):7649-66.

[25] Iglesias G, Carballo R. Offshore and inshore wave energy assessment: Asturias (N Spain). Energy 2010;35(5):1964-72.

[26] Neill SP, Hashemi MR. Wave power variability over the northwest European shelf seas. Appl Energy 2013;106(0):31-46.

[27] Iglesias G, Carballo R. Wave resource in El Hierro-an island towards energy self-sufficiency. Renew Energy 2011;36(2):689-98.

[28] Sierra JP, González-Marco D, Sospedra J, Gironella X, Mösso C, SánchezArcilla A. Wave energy resource assessment in Lanzarote (Spain). Renew Energy 2013;55(0):480-9.

[29] Iglesias G, Carballo R. Wave power for La Isla Bonita. Energy 2010;35(12): 5013-21.

[30] González-Marco D, Sierra JP, Fernández de Ybarra O, Sánchez-Arcilla A. Implications of long waves in harbor management: the Gijón port case study. Ocean Coast Manag 2008;51(2):180-201.

[31] Veigas M, Iglesias G. Wave and offshore wind potential for the island of Tenerife. Energy Convers Manag 2013;76:738-45.

[32] Pilar P, Soares CG, Carretero JC. 44-year wave hindcast for the North East Atlantic European coast. Coast Eng 2008;55(11):861-71. 